Network Working Group

Request for Comments: 2240

O. Vaughan

Category: Informational

\title{
A Legal Basis for Domain Name Allocation
}

Status of this Memo

This memo provides information for the Internet community. It does not specify an Internet standard of any kind. Distribution of this memo is unlimited.

Copyright Notice

Copyright (C) The Internet Society (1997). All Rights Reserved.

Table of Contents

1. Introduction . . . . . . . . . . . . . . . . . . . . 1

2. Overview of the domain space . . . . . . . . . . . . . . 2

3. Possible solutions to name exhaustion . . . . . . . . . . 3

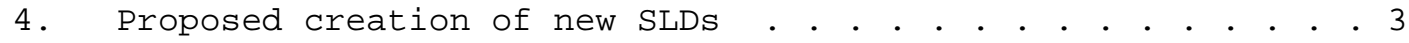

4.1 The world is not flat so why should domains be? . . . . . 4

4.2 The case for legal names . . . . . . . . . . . . . . . . 4

4.3 Allocation of legal SLDs . . . . . . . . . . . . . . . . . 4

4.4 Allocation of miscellaneous SLDs . . . . . . . . . . . . . 5

4.5 Identifiers in non-ASCII languages . • • • • • • • • • • • 5

5. Security Considerations . . . . . . . . . . . . . . . . 5

6. References . . . . . . . . . . . . . . . . . . 6

7. Authors' Address . . . . . . . . . . . . . . . . . 6

8. Full Copyright Statement . . . . . . . . . . . . . . . . . 7

\section{Introduction}

The purpose of this memo is to focus discussion on the particular problems with the exhaustion of the top level domain space in the Internet and the possible conflicts that can occur when multiple organisations are vying for the same name. No proposed solutions in 
this document are intended as standards for the Internet. Rather, it is hoped that a general consensus will emerge as to the appropriate solution to such problems, leading eventually to the adoption of standards.

2. Overview of the domain space

Presently the domain space is organised as a heirarchical treestructured namespace with several top level domains (TLDs), and subdomains beneath them. The initial TLDs allocated and rationale are documented in [1].

The TLDs are functionally split up into 'generic' top-level domains (gTLDs) and two-letter ISO 3166 country domains for every country in which Internet connectivity is provided. The allocation of subdomains under these TLDs is entirely up to the registry for that TLD. The registry may decide to allocate further levels of structure or merely allocate domains in a 'flat' manner.

Example:
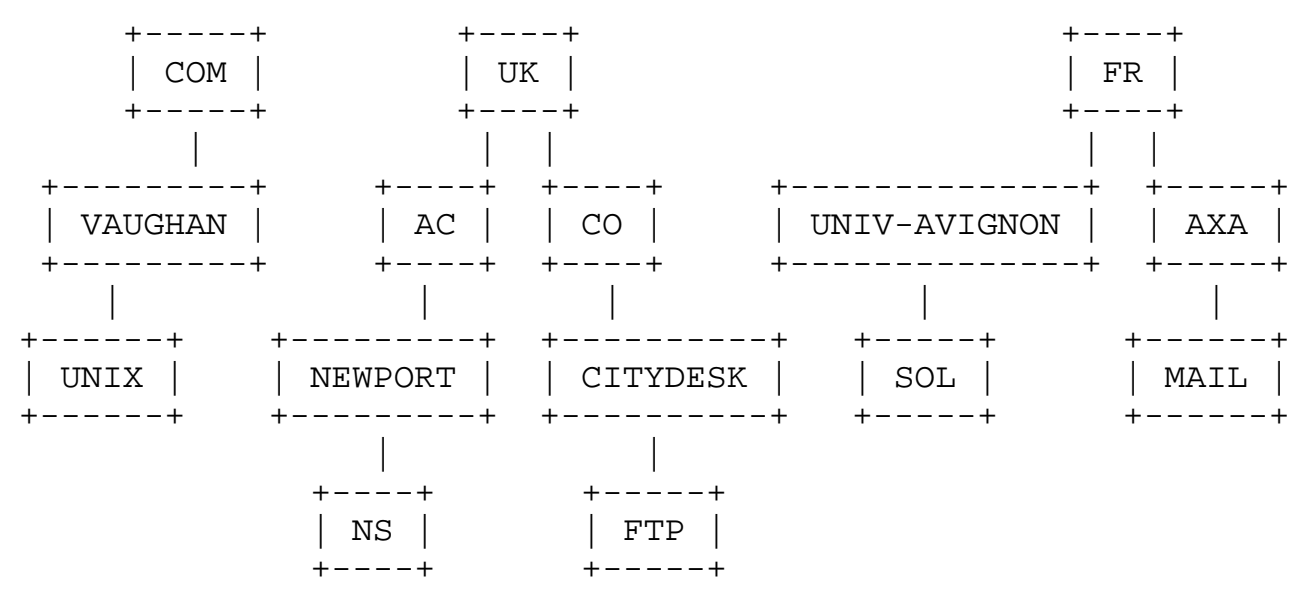

1. Flat gTLD

2. Heirarchical country

3. Flat country

In the example we see that the gTLDs are inherently flat, as organisations are allocated domain names directly under the TLD. With the country domains however, the domain allocation policy can vary widely from country to country, and it does. Some may choose to implement a functional sub-structure mirroring the gTLDs, some may choose to implement a geographical sub-structure, and some may choose to have no sub-structure at all. 
In the first case the organisation is clearly a commercial one, as it is allocatged under the "COM" TLD. However, there is no information as to the country the organisation is based in. In the third case, we know that the organisation is based in France (FR), but without studying the actual organisation name we do not know what type of organisation it is. In the second case, we know the country that both organisations are based in (UK), and by following the heirarchy, we can deduce that the first is an academic organisation (AC), and the second is commercial (CO).

While the system is flexible in not enforcing a strict heirarchy, it can lead to exhaustion of domain names in the generic space and lead to conflicts between organisations who may both have a legitimate claim to have a particular name.

3. Possible solutions to name exhaustion

With such a flexible system, there are many ways of preventing the name space being exhausted. A solution proposed by [2] is to create more gTLDs to allow organisations with the same name to be registered uniquely under different TLDs (FIRM, STORE, WEB, ARTS, REC, INFO and NOM) . However this has several disadvantages as discussed below:

a) It creates confusion in users mind as to what TLD refers to a particular organisation. For example, MCDONALDS.COM maybe the fast food corporation and MCDONALDS.FIRM maybe a firm of lawyers, but how is the user supposed to know which is which?

b) To prevent the above confusion, big corporations will simply reserve all the different variations of the name, ie. IBM.COM, IBM.FIRM, IBM.STORE etc. Thus we haven't solved the name exhaustion or conflict problems, in fact we have made it worse.

c) Names of legitimate trade mark holders or other legally held names can still be acquired by anybody, leading to potential conflicts.

4. Proposed creation of new SLDs

With the aforementioned problems in mind, it is not a good idea to create new gTLDs which merely overlap the existing ones. As the domain name system is heirarchical it would seem a good idea to expand on the existing structure rather than creating several duplicate structures. 
4.1 The world is not flat so why should domains be?

With the expansion of the Internet to a truly global medium, the notion that there can only be one commercial entity, one orgnisation, and one network provider etc. with the same name seems impossible. This is the situation that the present system finds itself in. There is a constantly spiralling number of disputes over who 'owns' or ' deserves' a certain name, with an increasing number ending in unnecessary and costly legal action. This is not something that the providers of a domain name service should concern themselves with, but yet with the present system, this seems inevitable.

\subsection{The case for legal names}

This proposal allows for country domain names that are related to legally registered names in the country that they are based by creating a functional heirarchy beneath the country TLD.

This proposal does not seek to do away with gTLDs, but rather that a legal name should be sought first and then, if desired, a generic name could be used alongside it. The organisation would then, in case of any disputes, have a legally-held name which no other organisation could have any claim to.

This proposal has several advantages:

a) The process of deciding what names belong to which organisation is no longer a function of the domain name registry, but of the company registration authority in the given country. This means that disputes over names cannot arise as all names are unique within the context of the legal company title.

b) As all names are unique, there should be no exhaustion (deliberately or otherwise) of 'desirable' names by other concerns, as all the owners of legally-held company names will automatically have the right to the relevant domain name.

\subsection{Allocation of legal SLDs}

The second level domain identifiers should be created from the existing company indentifiers within the given country. For example:

LTD.UK for limited companies in the UK
PLC.UK for public companies in the UK
INC.US for incorpated bodies in the US
CORP.US for corporations in the US
GMBH.DE for German companies


The registries for the appropriate top-level country domain should create and manage the sub-domains based on the laws for allocating company names in that particular country. Specifically, ALL spaces should be converted to hyphens ' - ' and other punctuation either disregarded or also converted into hyphens.

For holders of international trademarks and other international names, the gTLD "INT" can be used in place of the country identifier. For example:

TM.INT \} for international trademarks

REG.INT \}

4.4 Allocation of miscellaneous SLDs

In countries that do not have existing sub-structure it is strongly recommended that along with the creation of legal SLDs described here, that other SLDs be created for commercial entities, organisations, and academic entities to reduce remaining conflicts from organisations that are not legally-registered companies.

For example:

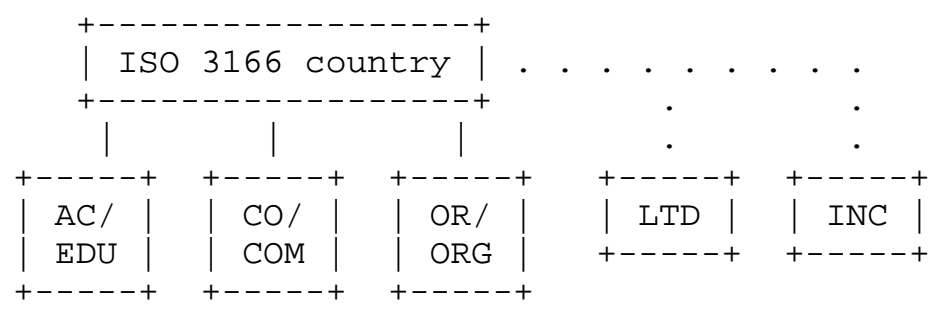

\subsection{Identifiers in non-ASCII languages}

The representation of any domain element is limited to the ASCII character set of alphabetic characters, digits and the hyphen, as described in [3]. The representation of names in languages that use other character sets is limited by that definition or any future update.

\section{Security Considerations}

This memo raises no issues relating to network security. However when delegating the subdomains, the registries must ensure that the application contains sufficient evidence of the legal rights to a given name. 
6. References

[1] Postel J. and J. Reynolds, "Domain Requirements", RFC 920, October 1984 .

[2] "Generic Top Level Domains - Memoranding of Understanding" <URL:http://www.gtld-mou.org/>

[3] Mockapetris, P., "Domain names - Implementation and Specification", RFC 1035, November 1987.

7. Author's Address

Owain Vaughan

Vaughan Enterprises

PO Box 155

Newport NP9 6YX

UK

Phone: +441633 677849/822164

Fax: +441633 663706

EMail: owainevaughan.com 
8. Full Copyright statement

Copyright (C) The Internet Society (1997). All Rights Reserved.

This document and translations of it may be copied and furnished to others, and derivative works that comment on or otherwise explain it or assist in its implementation may be prepared, copied, published and distributed, in whole or in part, without restriction of any kind, provided that the above copyright notice and this paragraph are included on all such copies and derivative works. However, this document itself may not be modified in any way, such as by removing the copyright notice or references to the Internet society or other Internet organizations, except as needed for the purpose of developing Internet standards in which case the procedures for copyrights defined in the Internet Standards process must be followed, or as required to translate it into languages other than English.

The limited permissions granted above are perpetual and will not be revoked by the Internet society or its successors or assigns.

This document and the information contained herein is provided on an "AS IS" basis and THE INTERNET SOCIETY AND THE INTERNET ENGINEERING TASK FORCE DISCLAIMS ALL WARRANTIES, EXPRESS OR IMPLIED, INCLUDING BUT NOT LIMITED TO ANY WARRANTY THAT THE USE OF THE INFORMATION HEREIN WILL NOT INFRINGE ANY RIGHTS OR ANY IMPLIED WARRANTIES OF MERCHANTABILITY OR FITNESS FOR A PARTICULAR PURPOSE. 